\section{Salt Stress-induced Injury is Associated with Hormonal Alteration in Kentucky Bluegrass}

\author{
Xunzhong Zhang ${ }^{1}$ \\ Department of Crop and Soil Environmental Sciences, Virginia Polytechnic \\ Institute and State University, Blacksburg, VA 24061
}

\begin{abstract}
Wenli Wu
Department of Crop and Soil Environmental Sciences, Virginia Polytechnic Institute and State University, Blacksburg, VA 24061; and Institute of Agricultural Environment and Resources, Shanxi Academy of Agricultural Sciences, Taiyuan 030006, Shanxi, People's Republic of China

\section{Erik H. Ervin and Chao Shang \\ Department of Crop and Soil Environmental Sciences, Virginia Polytechnic Institute and State University, Blacksburg, VA 24061}

\section{Kim Harich \\ Department of Biochemistry, Virginia Polytechnic Institute and State University, Blacksburg, VA 24061}

Additional index words. abiotic stress, cytokinins, turfgrass

\begin{abstract}
Plant hormones play an important role in plant adaptation to abiotic stress, but hormonal responses of cool-season turfgrass species to salt stress are not well documented. This study was carried out to investigate the responses of hormones to salt stress and examine if salt stress-induced injury was associated with hormonal alteration in kentucky bluegrass (KBG, Poa pratensis $\mathrm{L}$.). The grass was grown in a growth chamber for 6 weeks and then subjected to salt stress $(170 \mathrm{~mm} \mathrm{NaCl})$ for 28 days. Salt stress caused cell membrane damage, resulting in photosynthetic rate $(\mathrm{Pn})$, chlorophyll $(\mathrm{Chl})$, and turf quality decline in KBG. Salt stress increased leaf abscisic acid (ABA) and ABA/cytokinin (CK) ratio; reduced trans-zeatin riboside (ZR), isopentenyl adenosine (iPA), and indole3-acetic acid (IAA), but did not affect gibberellin A4 (GA4). On average, salt stress reduced ZR by $67.4 \%$ and IAA by $58.6 \%$, whereas it increased ABA by $398.5 \%$. At the end of the experiment (day 28), turf quality, Pn, and stomatal conductance $\left(g_{s}\right)$ were negatively correlated with $\mathrm{ABA}$ and $\mathrm{ABA} / \mathrm{CK}$ ratio, but positively correlated with $\mathrm{ZR}$, iPA, and IAA. Electrolyte leakage (EL) was positively correlated with $A B A$ and $A B A / C K$ and negatively correlated with ZR, iPA, IAA, and GA4. GA4 was also positively correlated with turf quality and $g_{\mathrm{s}}$. The results of this study suggest that salt stressinduced injury of the cell membrane and photosynthetic function may be associated with hormonal alteration and imbalance in KBG.
\end{abstract}

Salinity is a major factor limiting plant growth and development of plants in many areas of the world. As population and potable water demand increase, water shortage is a major problem in many parts of the world (Huang et al., 2014; Marcum and Pessarakli, 2010; Sun et al., 2015). Turfgrasses increasingly experience salt stress because of the accelerated salinization of agricultural lands and increasing demand on the use of reclaimed or other secondary saline water for irrigation of turfgrass landscapes (Huang et al., 2014; Jiang et al., 2013; Sun et al., 2015). Salt stress may reduce turfgrass growth and quality by osmotic stress-

Received for publication 22 Aug. 2017. Accepted for publication 9 Nov. 2017.

We would like to thank Kevin Liu and Naina Sharma for the help with lab work.

${ }^{1}$ Corresponding author. E-mail: xuzhang@vt.edu. induced injury. In many areas with limited fresh water resources, reclaimed water has been applied on golf courses and other turf surfaces to save water.

The complex regulatory processes of plant salt adaptation involve control of water flux, cellular osmotic adjustment, and hormonal regulation (Golldack et al., 2014; Ryu and Cho, 2015). The decline of cell $\psi_{\mathrm{S}}$ under salt stress may induce stomatal closure $(\mathrm{Hu}$ et al., 2013). However, excess accumulation of ions such as $\mathrm{Na}^{+}$under salt stress may cause toxicity to cells. In addition, salt stress may damage plant physiological processes by over accumulation of reactive oxygen species, impairment of antioxidant defense systems and photosynthetic function, and imbalance of hormones (Hu et al., 2012, 2015; Kim et al., 2016).

Plant hormones function as central integrators that link and reprogram the complex developmental and stress adaptive signaling cascade (Golldack et al., 2014; Llanes et al., 2016; Ryu and Cho, 2015; Strivastava, 2002). Elevated ABA may help plants to acclimate to low water availability by closing stomata (Man et al., 2011; Zhang et al., 2015). Cytokinins (such as ZR and iPA) essentially regulate various plant developmental processes, including cell division and enlargement, chloroplast biogenesis, nutrient mobilization, leaf senescence, vascular differentiation, and apical dominance (Ryu and Cho, 2015). Cytokinins facilitate the responses to delay both stomatal closure and leaf senescence under abiotic stresses (Ryu and Cho, 2015; Zhang et al., 2015). Auxins such as IAA can promote root initiation and also delay plant senescence (Zhang et al., 2009). Among the 136 known GAs, only GA1, GA3, GA4, GA5, GA6, and GA7 have intrinsic biological activity (Davies, 2010). Bioactive GAs such as GA4 are involved in plant growth and development such as leaf expansion, stem elongation, and flowering (Ryu and Cho, 2015). GA4 is two orders of magnitude more active in delaying leaf senescence of Alstroemeria hybrida than GA1 (Davies, 2010). It may be possible that GA4 may delay plant senescence under salt stress. There is cross-talking between GA action and other hormones signaling during abiotic stress to control plant growth and development (Ryu and Cho, 2015). It has been reported that salt stress induced an increase in ABA of maize (Zea mays L.) plants (Jia et al., 2002) and a reduction in IAA of maize (Fahad and Bano, 2012) and CKs in barley (Hordeum vulgare L.; Kuiper et al., 1990). However, limited research has been reported on the relationship of hormonal responses to salt stress with photosynthetic function and visual quality in cool-season turfgrass species.

Kentucky bluegrass (Poa pratensis L.) is one of the most important cool-season turfgrass species in temperate climates and widely used for home lawns, golf courses, urban landscapes, and other sports fields. However, the KBG quality declines because of salt stress in many areas (Huang et al., 2014). The objective of this study was to investigate the responses of hormones (IAA, ABA, ZR, iPA, and GA4) to salt stress and examine if salt stress-induced damage was associated with alteration of hormonal metabolism in KBG.

\section{Materials and Methods}

Plant materials and culture. This study was conducted in the growth chamber facility at Virginia Tech, Blacksburg, VA. Mature KBG ('Wildhorse', relatively salt tolerant) plugs $(10 \mathrm{~cm}$ diameter, $5 \mathrm{~cm}$ deep) were collected from the field plots at Virginia Tech Turfgrass Research Center, Blacksburg, VA, on Dec. 2015. The grass was transplanted into pots $(15 \mathrm{~cm}$ diameter, $15 \mathrm{~cm}$ deep, with eight holes on the bottom) filled with United States Golf Association (USGA)-specification sand with $10 \%$ peat by volume. A piece of plastic screen was placed at the bottom of the pot to prevent 
sand from leaching. The grass was grown in growth chambers under optimum conditions (mean $\pm \mathrm{SD}$ ) at $22 \pm 0.8 / 16 \pm 0.6{ }^{\circ} \mathrm{C}$ (day/ night), $70 \% \pm 8 \%$ relative humidity, photosynthetically active radiation $(P A R)$ of $400 \pm$ $9 \mu \mathrm{mol} \cdot \mathrm{m}^{-2} \cdot \mathrm{s}^{-1}$, and a $12-\mathrm{h}$ photoperiod. Nitrogen was applied at $2 \mathrm{~g} \cdot \mathrm{m}^{-2}$ (from 288-18 complete fertilizer with micronutrients) at transplanting and then $1 \mathrm{~g} \cdot \mathrm{m}^{-2}$ biweekly on all treatments until the end of the trial. The grass was trimmed to $7 \mathrm{~cm}$ and irrigated two times a week to field capacity.

Salt treatments and sampling. Six weeks after transplanting, the grass was subjected to either no-salt $(0 \mathrm{~mm} \mathrm{NaCl})$ or salt stress $(170 \mathrm{~mm} \mathrm{NaCl})$ treatments. Based on the previous reports (Xu and Fujiyama, 2013) and our preliminary trial, the salt concentration $(170 \mathrm{~mm} \mathrm{NaCl})$ was suitable for 'Wildhorse' KBG treatment. The salt solution was added in gradually increasing concentrations in aliquots of $45 \mathrm{~mm}$ every $12 \mathrm{~h}$ until the concentration of $170 \mathrm{~mm}$ was attained, and concentrations were maintained by measuring the conductivity of the growth media. Then each pot was placed in a plastic tray $(15 \mathrm{~cm}$ diameter, $15 \mathrm{~cm}$ deep) filled with either the salt treatment solution or distilled water only. The grass receiving the same volume of water served as control.

Leaf samples were collected at $0,4,7,14$, 21 , and $28 \mathrm{~d}$ after the initiation of stress treatment, and the samples were frozen with liquid $\mathrm{N}$ and stored at $-80{ }^{\circ} \mathrm{C}$ for analysis of various hormones. In addition, a small amount of fresh leaf tissue was collected for EL analysis.

Turf quality. Turf quality was rated based on a visual scale of 1 to 9 , with 1 indicating complete brown and 9 indicating a dark green color, and 6 being considered as minimum acceptable.

Leaf EL. Fresh leaves $(50 \mathrm{mg})$ were placed in a closed test tube containing $10 \mathrm{~mL}$ deionized water and electrical conductance (EC1) was measured after shaking on a rotary shaker for $24 \mathrm{~h}$ at room temperature. Then the samples were subjected to $120{ }^{\circ} \mathrm{C}$ for $30 \mathrm{~min}$ in an autoclave and EC2 was measured again. The leaf EL was calculated as follows:

$$
\mathrm{EL}(\%)=(\mathrm{EC} 1 / \mathrm{EC} 2) \times 100 \% .
$$

Leaf Chl content. Leaf Chl was extracted in acetone. Chlorophyll content was measured using a spectrophotometer according to Zhang et al. (2005b).

$P n$ and $\mathrm{g}_{s}$. Leaf Pn and $g_{\mathrm{s}}$ were measured using a portable photosynthetic system (LI6400XT; LI-COR Corporation, Lincoln, NE). Four uniform leaf blades were sampled from each pot and placed in the gas chamber for measurement with settings of $22^{\circ} \mathrm{C}, \mathrm{CO}_{2}$ flow rate of $400 \mu \mathrm{mol} \cdot \mathrm{s}^{-1}, \mathrm{CO}_{2}$ concentration of 385 $\mu \mathrm{mol} \cdot \mathrm{mol}^{-1}$, and $P A R$ of $800 \mu \mathrm{mol} \cdot \mathrm{m}^{-2} \cdot \mathrm{s}^{-1}$. Three readings from each sample were recorded and the average was used for statistical analysis.

Hormone extraction and purification. Leaf hormones (IAA, ZR, iPA, ABA, and GA4) were extracted according to Edlund

Table 1. Parameters for the analysis of leaf indole-3-acetic acid (IAA), $\mathrm{C}^{13}$-labeled IAA, abscisic acid (ABA), trans-zeatin riboside (ZR), isopentenyl adenosine (iPA), and gibberellin A4 (GA4) using liquid chromatography-mass spectrometry/mass spectrometry (LC-MS/MS).

\begin{tabular}{|c|c|c|c|c|c|c|}
\hline Analyte & Retention time (min) & Precursor ion & Product ion & Application & Collision energy & Mode \\
\hline \multirow[t]{2}{*}{$\overline{\mathrm{IAA}}$} & 3.9 & 176.1 & 130.2 & Quantitative & 12 & + \\
\hline & & & 77.2 & Qualitative & 52 & + \\
\hline \multirow[t]{2}{*}{$\mathrm{C}^{13}$-IAA } & 3.9 & 182.1 & 136.2 & Quantitative & 12 & + \\
\hline & & & 83.2 & Qualitative & 52 & + \\
\hline \multirow[t]{2}{*}{$\mathrm{ABA}$} & 4.6 & 265.2 & 229.2 & Quantitative & 0 & + \\
\hline & & & 91.2 & Qualitative & 4 & + \\
\hline \multirow[t]{2}{*}{ ZR } & 2.3 & 352.2 & 220.0 & Quantitative & 16 & + \\
\hline & & & 136.2 & Qualitative & 32 & + \\
\hline \multirow[t]{2}{*}{ iPA } & 4.3 & 336.0 & 204.0 & Quantitative & 20 & + \\
\hline & & & 136.0 & Qualitative & 30 & + \\
\hline \multirow[t]{2}{*}{ GA4 } & 6.0 & 331.3 & 213.2 & Quantitative & 35 & - \\
\hline & & & 269.1 & Qualitative & 20 & - \\
\hline
\end{tabular}

et al. (1995) and Zhang et al. (2009) with some modifications. Leaf tissues of each sample were ground with a mortar and pestle in liquid $\mathrm{N}_{2}$ to powder. The sample $(50 \mathrm{mg})$ was extracted in $1.6 \mathrm{~mL} \mathrm{Na-phosphate} \mathrm{buffer}$ (0.05 M, pH 7.0) containing $0.02 \%$ sodium diethyldithiocarbamate as an antioxidant, and the hormones were extracted for $1 \mathrm{~h}$ at $4{ }^{\circ} \mathrm{C}$ with shaking. The $\mathrm{C}^{13}$-IAA (50 ng) was added into each sample as an internal standard. The $\mathrm{pH}$ of the samples was adjusted to 2.6 with $1.0 \mathrm{M} \mathrm{HCl}$. The samples were slurried with $150 \mathrm{mg}$ Amberlite XAD-7 (Sigma-Aldrich, St. Louis, MO) for $30 \mathrm{~min}$. After removal of the buffer, the XAD-7 was washed two times with $1 \mathrm{~mL}$ of $1 \%$ acetic acid before being slurried two times with $1.5 \mathrm{~mL}$ dichloromethane for $30 \mathrm{~min}$ each at $4{ }^{\circ} \mathrm{C}$ (Edlund et al., 1995). The combined dichloromethane fractions were reduced to dryness with nitrogen gas. Then the samples were dissolved in $210 \mu \mathrm{L}$ methanol and diluted with $490 \mu \mathrm{L}$ deionized $\mathrm{H}_{2} \mathrm{O}$ containing $0.1 \%$ formic acid. The samples were filtered using an Acrodisc 13-mm syringe filter with a $0.2-\mathrm{mm}$ nylon membrane (Fisher Scientific Company, Pittsburgh, PA).

Hormone analysis by liquid chromatography-mass spectrometry/mass spectrometry (LC-MS/MS). An Agilent tandem LC-MS/MS system with an ESI sample introduction interface (Agilent, Santa Clara, CA), consisting of 1290 UPLC and 6490 QQQ, was used for analyzing IAA and ABA in extracts. High-performance liquid chromatography separation was performed on Agilent Zorbax Extend-C18 analytical $(4.6 \times 50 \mathrm{~mm}, 5 \mu \mathrm{m})$ and guard $(4.6 \times$ $12 \mathrm{~mm}, 5 \mu \mathrm{m})$ columns. The analytes were eluted with water (mobile phase A) and methanol (B) in $0.1 \%$ formic acid in a gradient: $0-4.5 \mathrm{~min} \mathrm{~B}$ increasing from $30 \%$ to $80 \%, 4.5-5 \mathrm{~min} \mathrm{~B}$ increasing to $100 \%$, $5-7 \mathrm{~min} \mathrm{~B}$ at $100 \%$, and B decreasing to $30 \%$ at $7.5 \mathrm{~min}$. The injecting volume was $10 \mu \mathrm{L}$ and flow rate was $0.5 \mathrm{~mL} \cdot \mathrm{min}^{-1}$. The column temperature was $40{ }^{\circ} \mathrm{C}$. The chromatography retention time (RT), precursor ion, fragmental reactions monitored, ionization mode, and collision energies used for each compound are given in Table 1 . The $\mathrm{C}^{13}$-labeled IAA $\left(\mathrm{IAA}_{\mathrm{d} 5}\right)$ was used as an internal standard. The source parameters were: nebulizer pressure $310 \mathrm{kPa}$, dry gas temperature $250{ }^{\circ} \mathrm{C}$, sheath

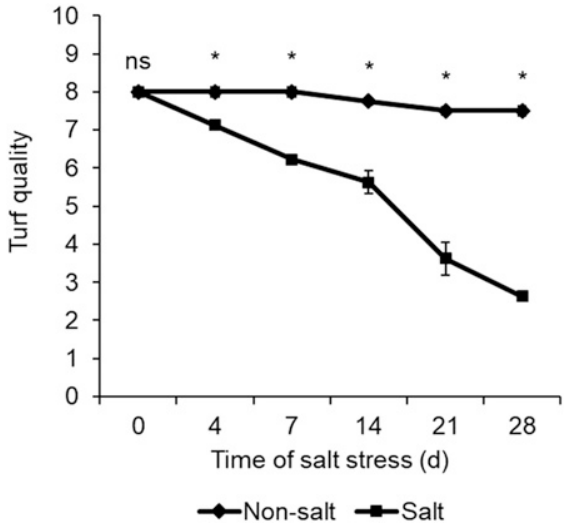

Fig. 1. Turf quality responses to salt stress in kentucky bluegrass. Bars represent SE, and * indicates that the difference between the two treatments for the given sampling date is significant at $P=0.05$.

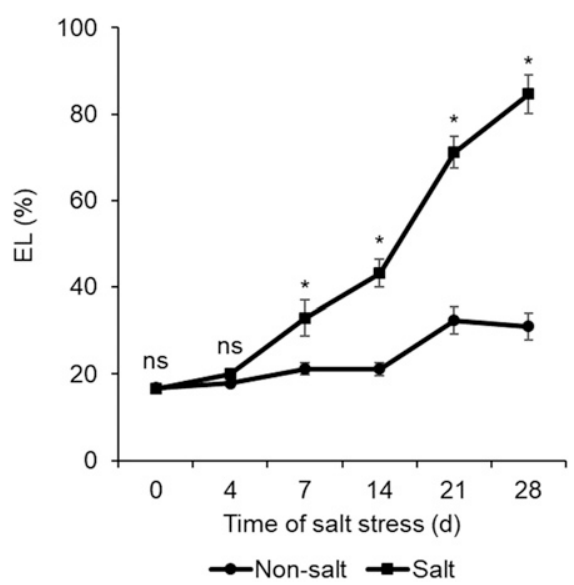

Fig. 2. Leaf electrolyte leakage (EL) responses to salt stress in kentucky bluegrass. Bars represent $\mathrm{SE}$, and * indicates that the difference between the two treatments for the given sampling date is significant at $P=0.05$.

gas temperature $200{ }^{\circ} \mathrm{C}$, and gas flow $8 \mathrm{~mL} \cdot \mathrm{min}^{-1}$. The selected hormones were determined based on the RT, ion products, and standards of each compound.

Experimental design and statistical analysis. The treatments were arranged in a completely randomized block design with four replications. The data were subjected to 
one-way analysis of variance using SAS software (v. 9.3 for Windows; SAS Institute, Cary, NC, 2010). Mean separations were performed using Fisher's protected least significant difference test at the $0.05 P$ level. Pearson's correlation coefficients of turf quality, EL, Pn, and $g_{\mathrm{s}}$ with various hormones and $\mathrm{ABA} / \mathrm{CK}$ were calculated using the SAS software.

\section{Results}

Turf quality. Salt stress reduced turf quality (Fig. 1). Turf quality started to decline at day 4 because of salt stress. At day 28 , salt stress reduced turf quality rating by $64.9 \%$ relative to the control.

Leaf EL. Salt stress increased EL (Fig. 2). The EL differences between salt stress and no-salt treatments were observed from day 7 through day 28 . At day 28 , salt stress increased it by $273.2 \%$ relative to the control.

Leaf Chl. Salt stress reduced Chl content at days 14, 21, and 28 (Table 2). At day 28, salt stress reduced $\mathrm{Chl}$ by $74.5 \%$ relative to the control.

Leaf $P n$ and $\mathrm{g}_{s}$. Salt stress reduced $\mathrm{Pn}$ (Fig. 3; Table 2). The Pn differences between salt stress and no-salt treatments were observed from day 4 through day 28 . At day 28 , salt stress reduced it by $90.7 \%$ relative to the control. Salt stress reduced $g_{\mathrm{s}}$ (Table 2). The $g$ s differences between salt stress and no-salt treatments were found from day 4 to day 28 . At day 28 , salt stress reduced it by $74.8 \%$ relative to the control.

Leaf $Z R$ and $i P A$ content. Salt stress reduced leaf ZR content (Fig. 4). The ZR differences between salt stress and no-salt treatments were observed from day 7 through day 28. At day 28 , salt stress reduced it by $67.4 \%$ relative to the control.

Salt stress reduced leaf iPA content (Fig. 5). The iPA differences between salt stress and no-salt treatments were observed from day 14 through day 28 . At day 28 , salt stress reduced it by $36.0 \%$ relative to the control.

Leaf IAA content. Salt stress reduced leaf IAA content (Fig. 6). The IAA differences between salt stress and no-salt treatments were observed from day 14 to day 28 . At day 28 , salt stress reduced it by $58.6 \%$ relative to the control.

Leaf $A B A$ content and $A B A / C K$ ratio. Salt stress reduced leaf ABA content (Fig. 7). The ABA differences between salt stress and nosalt treatments were found from day 7 to day 28. At day 28, salt stress reduced it by $398.5 \%$ relative to the control. The ratio of ABA to CK (ZR + iPA) increased from 0.72 to 5.33 because of salt stress at day 28 .

Leaf GA4 content. No difference in leaf GA4 between no-salt and salt stress treatments was observed regardless of the sampling date (Table 2).

Relationship of hormone level with turf performance. At the end of the experiment (day 28), turf quality, $\mathrm{Pn}$, and $g_{\mathrm{s}}$ were negatively correlated with $\mathrm{ABA}$ and $\mathrm{ABA} /$ $\mathrm{CK}$ ratio, but positively correlated with $\mathrm{ZR}$,
Table 2. Leaf chlorophyll (Chl), stomatal conductance $\left(g_{\mathrm{s}}\right)$, and gibberellin A4 (GA4) responses to salt stress in kentucky bluegrass.

\begin{tabular}{|c|c|c|c|c|c|c|}
\hline Treatment & 0 & 4 & 7 & 14 & 21 & 28 \\
\hline \multicolumn{7}{|c|}{$\overline{\mathrm{Chl}}\left(\mathrm{mg} \cdot \mathrm{g}^{-1} \mathrm{FW}\right)$} \\
\hline No-salt & $2.76 \mathrm{a}$ & $2.74 \mathrm{a}$ & $2.07 \mathrm{a}$ & $2.02 \mathrm{a}$ & $2.31 \mathrm{a}$ & $2.12 \mathrm{a}$ \\
\hline Salt & $2.66 \mathrm{a}$ & $2.61 \mathrm{a}$ & $1.99 \mathrm{a}$ & $1.16 \mathrm{~b}$ & $0.80 \mathrm{~b}$ & $0.54 \mathrm{~b}$ \\
\hline \multicolumn{7}{|c|}{$g_{\mathrm{s}}\left(\mathrm{mol} \mathrm{H} \mathrm{H}_{2} \mathrm{O} / \mathrm{m}^{2} / \mathrm{s}\right)$} \\
\hline No-salt & $0.119 \mathrm{a}$ & $0.119 \mathrm{a}$ & $0.167 \mathrm{a}$ & $0.190 \mathrm{a}$ & $0.210 \mathrm{a}$ & $0.202 \mathrm{a}$ \\
\hline Salt & $0.147 \mathrm{a}$ & $0.069 \mathrm{~b}$ & $0.069 \mathrm{~b}$ & $0.038 \mathrm{~b}$ & $0.025 \mathrm{~b}$ & $0.051 \mathrm{~b}$ \\
\hline \multicolumn{7}{|c|}{ GA4 (ng.g $\left.{ }^{-1} \mathrm{FW}\right)$} \\
\hline No-salt & $10.63 \mathrm{a}$ & $12.90 \mathrm{a}$ & $12.50 \mathrm{a}$ & $14.25 \mathrm{a}$ & $11.50 \mathrm{a}$ & $7.95 \mathrm{a}$ \\
\hline Salt & $38.40 \mathrm{a}$ & $10.70 \mathrm{a}$ & $9.80 \mathrm{a}$ & $11.73 \mathrm{a}$ & $9.78 \mathrm{a}$ & $7.55 \mathrm{a}$ \\
\hline
\end{tabular}

Means followed by same letters within the same column for each data set are not significantly different at $P=0.05$.

$\mathrm{FW}=$ fresh weight.

iPA, and IAA (Table 3). The EL was positively correlated with $\mathrm{ABA}$ and $\mathrm{ABA} / \mathrm{CK}$ and negatively correlated with ZR, iPA, IAA, and GA4. GA4 was also positively correlated with turf quality and $g_{\mathrm{s}}$.

\section{Discussion}

The results of this study showed that salt stress $(170 \mathrm{~mm} \mathrm{NaCl})$ caused significant damage to KBG. The salt stress damaged cell membrane integrity (higher EL) and photosynthetic function (lower Pn), resulting in decline in leaf Chl and turf quality. This is in general agreement with previous studies by Puyang et al. (2016) and Xu and Fujiyama (2013) with KBG. Hu et al. (2013) reported that salt stress may cause damage to perennial ryegrass through stomatal limitation. Saltinduced osmotic stress may cause stomatal closure and inhibits gas exchange, resulting in oxidative damage of cell membrane and photosynthetic function.

Our results showed that the decline in Pn and turf quality due to salt stress was observed as early as day 4 . At the same time, $g_{\text {s }}$ declined rapidly (as measured at day 4) in response to salt stress. Liu et al. (2011) reported that salt stress $(300$ and $500 \mathrm{~mm}$ $\mathrm{NaCl}$ ) reduced $g_{\mathrm{s}}$ and $\mathrm{Pn}$ of centipedegrass [Eremochloa ophiuroides (Munro) Hack] beginning at day 4 of salt treatment. This suggests that hormones and other molecules may induce stomatal closure, resulting in cell membrane damage, and decline in photosynthetic function and visual quality as signal molecules at the early stage of stress.

Plant hormones play an important role in regulating plant tolerance to salt stress (Davies, 2010, Huang et al., 2014; Ryu and Cho, 2015). The results of this study indicated that salt stress increased $\mathrm{ABA}$ content and $\mathrm{ABA} / \mathrm{CK}$ ratio, reduced levels of IAA, $\mathrm{ZR}$, and iPA; and did not affect GA4. The differences in ABA content between salt stress and no-salt treatments were detected as early as day 4 .

The $\mathrm{ABA}$ level and $\mathrm{ABA} / \mathrm{CK}$ ratio were negatively correlated with $\mathrm{Pn}, g_{\mathrm{s}}$, and turf quality, but positively correlated with EL as measured at the end of salt stress. Gao and $\mathrm{Li}$ (2014) reported that salt-tolerant tall fescue exhibited slower ABA accumulation rate than sensitive cultivars during short-term salt stress. This suggests that the slow and low

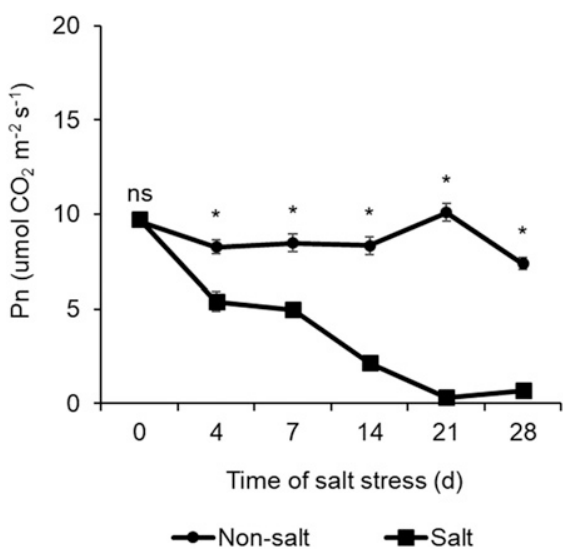

Fig. 3. Leaf photosynthetic rate $(\mathrm{Pn})$ responses to salt stress in kentucky bluegrass. Bars represent $\mathrm{SE}$, and * indicates that the difference between the two treatments for the given sampling date is significant at $P=0.05$.

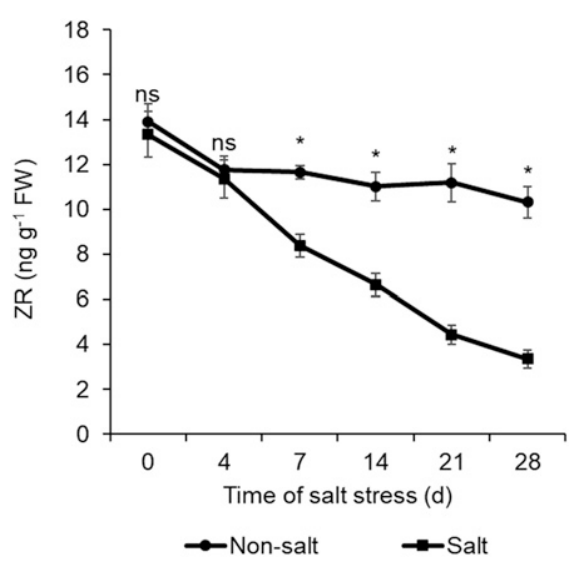

Fig. 4. Leaf zeatin riboside (ZR) responses to salt stress in kentucky bluegrass. Bars represent SE, and $*$ indicates that the difference between the two treatments for the given sampling date is significant at $P=0.05$.

accumulation rate of $\mathrm{ABA}$ in leaves could be beneficial for the maintenance of Pn under salt stress.

The results of this study indicated that CKs were positively correlated with turf quality, Pn, and $g_{\mathrm{s}}$, but negatively correlated with EL at day 28. Cytokinins may have antagonistic effects with ABA in controlling 


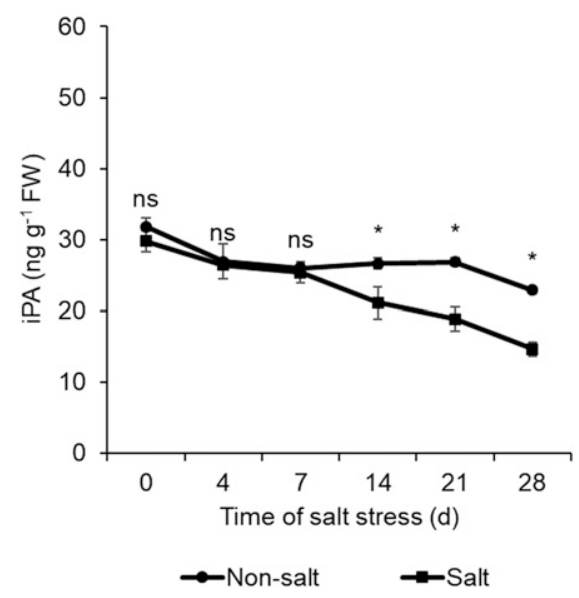

Fig. 5. Leaf isopentenyl adenosine (iPA) responses to salt stress in kentucky bluegrass. Bars represent $\mathrm{SE}$, and $*$ indicates that the difference between the two treatments for the given sampling date is significant at $P=0.05$.

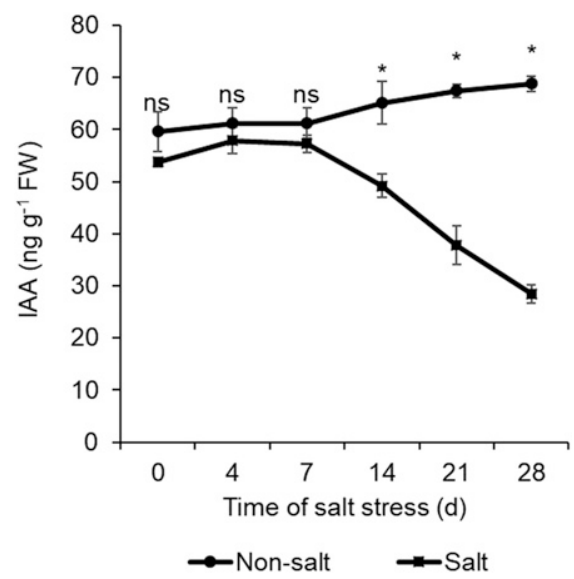

Fig. 6. Leaf indole-3-acetic acid (IAA) responses to salt stress in kentucky bluegrass. Bars represent SE, and * indicates that the difference between the two treatments for the given sampling date is significant at $P=0.05$.

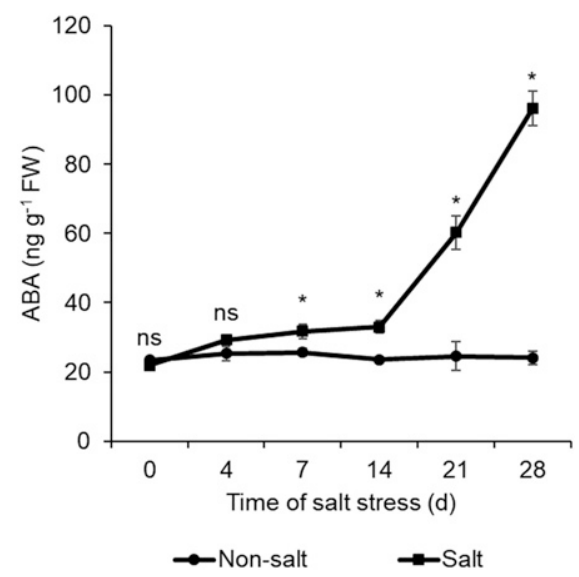

Fig. 7. Leaf abscisic acid (ABA) responses to salt stress in kentucky bluegrass. Bars represent SE, and $*$ indicates that the difference between the two treatments for the given sampling date is significant at $P=0.05$.

Table 3. Correlations of turf quality, electrolyte leakage (EL), photosynthetic rate (Pn), and stomatal conductance $\left(g_{\mathrm{s}}\right)$ with various hormones.

\begin{tabular}{|c|c|c|c|c|c|c|}
\hline & $\mathrm{ABA}$ & ZR & iPA & $\mathrm{ABA} / \mathrm{CK}^{\mathrm{z}}$ & IAA & GA4 \\
\hline & \multicolumn{6}{|c|}{ Pearson correlation coefficient $(r)$} \\
\hline$\overline{\text { Quality }}$ & $-0.939^{* * y}$ & $0.966^{* *}$ & $0.971^{* *}$ & $-0.927 * *$ & $0.974 * *$ & $0.717^{*}$ \\
\hline EL & $0.907 *$ & $-0.946 * *$ & $-0.942 * *$ & $0.888^{*}$ & $-0.958 * *$ & $-0.751^{*}$ \\
\hline Pn & $-0.932 * *$ & $0.973 * *$ & $0.954^{* *}$ & $-0.921 * *$ & $0.957 * *$ & $0.688 \mathrm{NS}$ \\
\hline$\underline{g_{\mathrm{s}}}$ & $-0.908 * *$ & $0.919^{* *}$ & $0.906 *$ & $-0.893^{*}$ & $0.937 * *$ & $0.820 *$ \\
\hline
\end{tabular}

stomatal behavior in response to salt stress, which ultimately affects $g_{\mathrm{s}}$ and transpiration rate (Davies, 2010; Huang et al., 2014). In addition, CK can delay leaf senescence, protect chloroplast, and, thus, impair photosynthetic function (Davies, 2010; Ryu and Cho, 2015). Plants with higher CK exhibit greater osmotic stress tolerance, and exogenously applied CK could improve drought tolerance in $\mathrm{KBG}$ and other cool-season turfgrass species (Zhang and Ervin, 2004; Zhang and Schmidt, 2000). Huang et al. (2014) indicated that the ratio of $\mathrm{ABA}$ to $\mathrm{CK}$ or balance of the two hormones may be more important for regulating gas exchange and water relations than the absolute level of either hormone. This suggests that both $\mathrm{ABA} / \mathrm{CK}$ ratio and the absolute value of each hormone may be associated with salt tolerance in KBG.

The results of this study showed that leaf IAA was positively correlated with turf quality, $\mathrm{Pn}$, and $g_{\mathrm{s}}$, but negatively correlated with EL. The IAA seems to be less sensitive to salt than $\mathrm{CK}$ and $\mathrm{ABA}$ because it started to decline $\approx 1-2$ weeks following $\mathrm{CKs}$ and $\mathrm{ABA}$ in responses to salt stress. The IAA is closely associated with root growth and also delays leaf senescence under stress (Zhang et al., 2009). Leaf tissue IAA content was positively correlated with drought tolerance, and exogenous application of indole-3-butyric acid (IBA) increased endogenous IAA, which improved osmotic stress tolerance in tall fescue (Zhang et al., 2005a). Zhang et al. (2009) noted that exogenous IBA increased root growth and endogenous CKs and auxin, and improved drought tolerance of tall fescue. Salt stress may reduce IAA because of either reduction in IAA biosynthesis or promotion of its degradation, resulting in less IAA and more severe senescence of leaf tissues.

The results of this study indicated that salt stress did not affect GA4. However, GA4 was positively correlated with turf quality, $g_{\mathrm{s}}$, but negatively correlated with EL. Maggio et al. (2010) found that exogenous GA3 enhanced water availability at low salt stress conditions. The results of this study suggest that GA4 may also affect $g_{\text {s }}$ and cell membrane integrity under salt stress.

In summary, salt stress $(170 \mathrm{~mm} \mathrm{NaCl})$ caused cell membrane damage, resulting in $\mathrm{Pn}, g_{\mathrm{s}}$, and visual quality decline in KBG. Salt stress increased leaf $\mathrm{ABA}$ and $\mathrm{ABA} / \mathrm{CK}$ ratio and reduced $Z R$, iPA, and IAA, but did not affect GA4. The increase in ABA and
$\mathrm{ABA} / \mathrm{CK}$ ratio and decline in $\mathrm{ZR}$, iPA, IAA, and GA4 were associated with salt stressinduced injury of cell membrane, turf quality, and photosynthetic function in KBG. Selection and use of cultivars with higher CK, IAA, and GA4 under salt stress or enhancement of the level of these hormones through exogenous applications may improve salt stress tolerance in $\mathrm{KBG}$.

\section{Literature Cited}

Davies, P.J. 2010. Plant hormones: Biosynthesis, signal transduction, action. 3rd ed. Springer, New York, NY.

Edlund, A., S. Eklof, B. Sundberg, T. Moritz, and G. Sandberg. 1995. A microscale technique for gas chromatography-mass spectrometry measurements of pictogram amounts of indole-3aceticv acid in plant tissues. Plant Physiol. 108:1043-1047.

Fahad, S. and A. Bano. 2012. Effect of salicylic acid on physiological and biochemical characterization of maize grown in saline area. Pak. J. Bot. 44:1433-1438.

Gao, Y. and D. Li. 2014. Growth responses of tall Fescue (Festuca arundinacea Schreb.) to salinity stress. Eur. J. Hort. Sci. 79(3):123-128.

Golldack, D., C. Li, H. Mohan, and N. Probst. 2014. Tolerance to drought and salt stress in plants: Unravelling the signaling networks. Front. Plant Sci. 5:151.

Hu, G., Y. Liu, X. Zhang, F. Yao, Y. Huang, E.H. Ervin, and B. Zhao. 2015. Physiological evaluation of alkali-salt tolerance of thirty switchgrass (Panicum virgatum) lines. PLoS One 10(7): 0125305

Hu, L., T. Hu, X. Zhang, H. Pang, and J. Fu. 2012. Exogenous glycine betaine ameliorates adverse effects of salt stress on perennial ryegrass. J. Amer. Soc. Hort. Sci. 137:38-46.

Hu, T., H. Yi, L. Hu, and J. Fu. 2013. Stomatal and metabolic limitations to photosynthesis resulting from $\mathrm{NaCl}$ stress in perennial ryegrass genotypes differing in salt tolerance. J. Amer. Soc. Hort. Sci. 138:350-357.

Huang, B., M. DaCosta, and Y. Jiang. 2014 Research advances in mechanisms of grass tolerance to abiotic stress: From physiology to molecular biology. Crit. Rev. Plant Sci. 33:141-189.

Jia, W., Y. Wang, S. Zhang, and J. Zhang. 2002. Salt stress-induced ABA accumulation is more sensitively triggered in roots than in shoots. J. Expt. Bot. 53:2201-2206.

Jiang, Y., J. Tang, X. Yu, and J. Camberato. 2013. Growth and physiological responses of diverse perennial ryegrass accessions to increasing salinity. Annu. Rep. Purdue Univ. Turfgrass Sci. Progr. 7-11.

Kim, J., Y. Liu, X. Zhang, B. Zhao, and K. Childs. 2016. Analysis of salt-induced physiological and proline changes in 46 switchgrass 
(Panicum virgatum) lines indicates multiple responses modes. Plant Physiol. Biochem. 105:203-212.

Kuiper, D., J. Schuit, and P.J.C. Kuiper. 1990. Actual cytokinin concentrations in plant tissue as an indicator for salt resistance in cereals. Plant Soil 123:243-250.

Llanes, A., A. Andrade, S. Alenabo, and V. Luna. 2016. Alterations of endogenous hormonal levels in plants under drought and salinity. Amer. J. Plant Sci. 7:1357-1371.

Liu, Y., H. Du, K. Wang, B. Huang, and Z. Wang. 2011. Differential photosynthetic responses to salinity stress between two perennial grass species contrasting in salinity tolerance. HortScience 46:311-316.

Maggio, A., G. Barbieri, G. Raimondi, and S. Pascale. 2010. Contrasting effects of GA3 treatments on tomato plants exposed to increasing salinity. J. Plant Growth Regul. 29:63-72.

Man, D., Y.X. Bao, L.B. Han, and X. Zhang. 2011. Drought tolerance associated with proline and hormone metabolism in two tall fescue cultivars. HortScience 46:1027-1032.
Marcum, K.B. and M. Pessarakli. 2010. Salinity tolerance of ryegrass turf cultivars. HortScience 45:1882-1884.

Puyang, X., M. An, L. Xu, L. Han, and X. Zhang. 2016. Protective effect of exogenous spermidine on ion and polyamine metabolism in Kentucky bluegrass under salinity stress. Hort. Environ. Biotechnol. 57:11-19.

Ryu, H. and Y. Cho. 2015. Plant hormones in salt stress tolerance. J. Plant Biol. 58:147-155.

Strivastava, L.M. 2002. Plant growth and development: Hormones and environment. Academic Press, San Diego, CA.

Sun, S., M. An, L. Han, and S. Yin. 2015. Foliar application of 24-epibrassinolide improved salt stress tolerance of perennial ryegrass. HortScience 50:1518-1523.

$\mathrm{Xu}, \mathrm{R}$. and H. Fujiyama. 2013. Comparison of ionic concentration, organic solute accumulation, and osmotic adaptation in Kentucky bluegrass and tall fescue under $\mathrm{NaCl}$ stress. Soil Sci. Plant Nutr. 59:168-179.

Zhang, X. and E.H. Ervin. 2004. Cytokinincontaining seaweed and humic acid extracts associated with creeping bentgrass leaf cytokinins and drought resistance. Crop Sci. 44:1737-1745.

Zhang, X., E.H. Ervin, G. Evanylo, C. Sherony, and C. Peot. 2005a. Biosolids impact on tall fescue drought resistance. J. Residuals Sci. Technol. 2:173-180.

Zhang, X., E.H. Ervin, and R.E. Schmidt. 2005 b. The role of leaf pigment and antioxidant levels in UV-B resistance of dark- and light-green kentucky bluegrass. J. Amer. Soc. Hort. Sci. 130:836-841.

Zhang, X., E.H. Ervin, G.K. Evanylo, and K.C. Haering. 2009. Impact of biosolids on hormone metabolism in drought-stresses tall fescue. Crop Sci. 49:364-370.

Zhang, X., E.H. Ervin, Y. Liu, G. Hu, C. Shang, T. Fukao, and J. Alpuerto. 2015. Differential responses of antioxidants, abscisic acid, and auxin to deficit irrigation in two perennial ryegrass cultivars contrasting in drought tolerance. J. Amer. Soc. Hort. Sci. 140:562-572.

Zhang, X. and R.E. Schmidt. 2000. Hormone containing products' impact on antioxidant status of tall fescue and creeping bentgrass subjected to drought. Crop Sci. 40:1344-1349. 